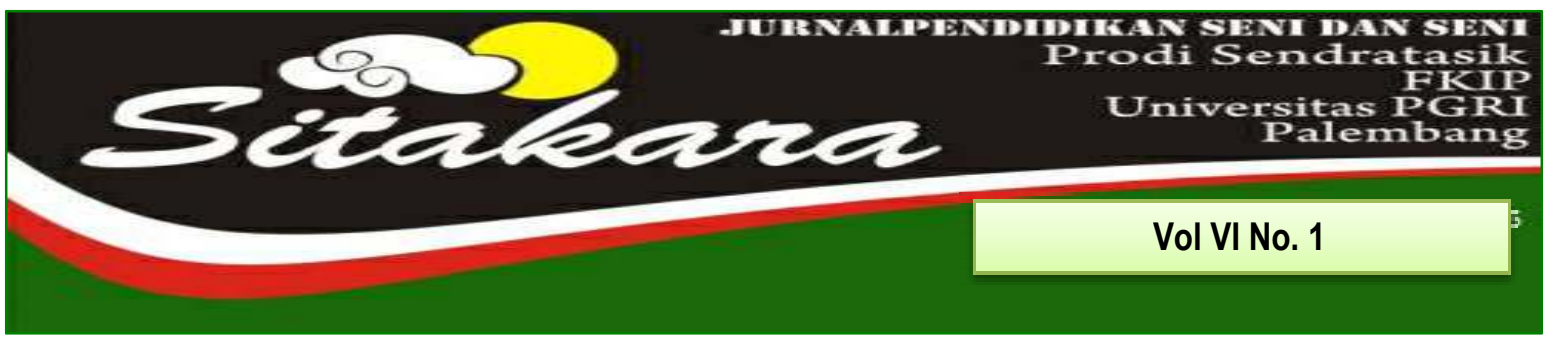

PERTUNJUKAN SOLIS MARIMBA DENGAN REPERTOAR THE VARIANTIONS ON THEME (FROM THE MALAY'S "PUCUK PISANG")

(Fery Herdianto)

BUKIT SIGUNTANG DALAM PENGEMBANGAN KONSEP RUANG KOREOGRAFI $\quad$ 13-26 LINGKUNGAN TARI

(Rully Rochayati, Eva Dina Chairunisa)

APLIKASI SIBELIUS SEBAGAI MEDIA PEMBELAJARAN DALAM MENULIS NOTASI MUSIK BERMAS

(Dedy Firmansyah \& Nugroho NAD)

PENGARUH MODEL PEMBELAJARAN EXPLICIT INSTRUCTION PADA 40-54 PEMBELAJARAN TARI DAERAH

(Treny Hera \& Efita Elvandari)

SIMBOLISASI ORNAMEN NAGA PADA PEMBATAS JALAN DI PALEMBANG (Decky Kunian \& A.Heryanto)

PENGARUH MODEL PEMBELAJARAN INSIDE-OUTSIDE-CIRCLE (IOC) TERHADAP WRITING SKILL DALAM TEKS MENULIS DRAMA DI SMP SETIA NEGARA PALEMBANG

(Sri Wahyu Indrawati \& Yuspar Uzer)

PEMANFAATAN TEKNOLOGI MULTIMEDIA DALAM PEMBELAJARAN MUSIK DI $79-87$ SMP N 1 PALEMBANG

(Novdaly Fillamenta \& Yuliza Aryani)

BENTUK PENYAJIAN ORKES GAMBUS SANGGAR MOZAIG PADA ACARA PERNIKAHAN ADAT ARAB PALEMBANG

(Auzy Madona Adoma)

PENINGKATAN KEMAMPUAN MEMBACA TEKS DRAMA DENGAN 100-111 MENGGUNAKAN METODE SPEED READING PADA PEMBELAJARAN BAHASA INDONESIA UNTUK SISWA SMPN 16 PALEMBANG (Wandiyo)

PELAKSANAAN EVALUASI PEMBELAJARAN SENI BUDAYA DI SMP 1 JEKULO 112-123 KUDUS PADA MASA PANDEMI COVID-19

M.Panji Wahyu Mukti \& Wahyu Lestari 
1. Naskah berbahasa Indonesia bertemakan Seni Budaya yang meliputi hasil penelitian pengajaran seni budaya, cabang seni, dan kebudayaan.

2. Naskah harus asli dan belum pernah dimuat dalam media lain. Naskah dapat berupa hasil penelitian perorangan atau kelompok.

3. Naskah ditulis dengan cara-cara yang sesuai dengan ketentuan penulisan artikel ilmiah menggunakan bahasa Indonesia yang baku, berupa ketikan, beserta soft line dalam CD-RW atau dengan mengirimkan email pada redaksi Jurnal SITARARA dengan alamat email: jurnalsitakarasendratasik@yahoo.com, spasi 1,5 jenis huruf Arrial Narrow ukuran 12, dengan panjang naskah antara 8-15 halaman pada kertas A4.

4. Artikel hasil penelitian memuat:

JUDUL

Nama Penulis

Abstrak

A. Pendahuluan

B. METODE PENELITIAN

C. HASIL DAN PEMBAHASAN

D. SIMPULAN
: XXX (HURUF KAPITAL)

: (disertai jabatan dan institusi)

: (Bahasa Indonesia yang memuat 100150 kata diikuti kata kunci, dengan jenis huruf Arrial Narrow dan ukuran huruf 11 spasi tunggal serta dicetak miring)

: (Memuat latar belakang masalah, tinjauan pustaka secara ringkas, masalah penelitian dan tujuan penelitian)

: (Berisi simpulan)

5. Artikel kajian konseptual memuat:

JUDUL

Nama Penulis

Abstrak

\section{: XXX (HURUF KAPITAL)}

: (disertai jabatan dan institusi)

: (Bahasa Indonesia yang memuat 100150 kata diikuti kata kunci, dengan jenis huruf Arrial Narrow dan ukuran huruf 11 serta dicetak miring)

PENDAHULUAN
: (Memuat latar belakang masalah, tinjauan pustaka secara ringkas, masalah penelitian dan tujuan penelitian) 
Sub Judul

Sub Judul

SIMPULAN

DAFTAR PUSTAKA
: Sesuai dengan kebutuhan (tanpa numbering)

: (Berisi simpulan dan saran)

: (Berisi pustaka yang dirujuk dalam uraian naskah

6. Referensi sumber dalam teks artikel ditulis dengan menggunakan side note, contoh: (Jalalluddin, 1991:79); (Taufik, 2005;350); (Hamid dan Madjid, 2011:43). Sementara penulisan daftar pustaka disusun dengan ketentuan. Nama Pengarang. Tahun Terbit. Judul (dicetak miring). Kota Terbit: Nama Penerbit. Contoh: Koentjaraningrat. 2010. Manusia dan Kebudayaan Di Indonesia. Jakarta: Djambatan.

Daftar pustaka hanya memuat pustaka/sumber yang dirujuk dalam uraian dan disusun menurut abjad, tanpa nomor urut.

7. Naskah yang dimuat akan disunting kembali oleh redaksi tanpa mengubah isinya.

8. Naskah yang ditolak (tidak bisa dimuat) akan dikirim kembali ke penulis dengan pemberitahuan tertulis dari redaksi atau alamat email.

9. Penulis yang naskahnya dimuat akan mendapatkan 1 (satu) majalah nomor yang bersangkutan.

10. Contact Person: Treny Hera (085357344704) dan Mainur (081373165553). 


\title{
PEMANFAATAN TEKNOLOGI MULTIMEDIA DALAM PEMBELAJARAN MUSIK DI SMP NEGERI 1 PALEMBANG
}

\author{
Oleh: \\ Novdaly Fillamenta ${ }^{1}$ \\ Yuliza Aryani \\ (APIKES Widya Dharma Palembang) \\ Email: fillamenta@gmail.com
}

\begin{abstract}
ABSTRAK
Penelitian ini bertujuan untuk mengetahui pemanfaatan teknolgi multimedia dalam pembelajaran Musik di SMP N 1 Palembang. Penelitian ini menggunakan desain statistik deskriptif. Populasi pada penelitian ini adalah semua siswa kelas VII di SMPN 1 Palembang yaitu sebanyak 90 orang tahun ajaran 2017/2018, pengambilan sampel menggunakan tehnik stratified random sampling yaitu pengambilan sample secara acak yang mewakili dari setiap strata atau tingkatan. Data diolah dengan menggunakan statistik deskriptif dengan metode regresi logistik melalui program komputerisasi. Hasil analisa menunjukkan bahwa pemanfaatan teknologi multimedia dalam pembelajaran Musik di SMPN 1 Palembang sangat baik.

Kata Kunci : Pemanfaatan Teknologi Multimedia, Pembelajaran Musik
\end{abstract}

\section{A. PENDAHULUAN}

Kegiatan pendidikan yang berlangsung di institusi menempatkan institusi tersebut sebagai salah satu institusi sosial. Begitu pula dengan kemajuan masyarakat modern dewasa ini, tidak mungkin dapat dicapai tanpa kehadiran institusi pendidikan sebagai organisasi yang menyelenggarakan pendidikan secara formal. Pada hakikatnya institusi pendidikan merupakan pusat kegiatan transper dan trasmisi ilmu pengetahuan antar akademis dari seorang narasumber kepada murid-muridnya atau sebaliknya (Syarafuddin \& Nasution, 2000).

Majunya teknologi informasi merupakan suatu perkembangan yang memberikan akses terhadap perubahan kehidupan masyarakat. Dunia informasi menjadi salah satu wilayah yang berkembang pesat dan banyak mempengaruhi peradaban masyarakat. Radio, televisi, DVD, VCD merupakan salah satu perangkat elektronik yang menjadi bagian dari perabot rumah tangga yang berfungsi sebagai informatif dan media 
entertainment yang memberikan pilihan hiburan menyegarkan, yang mengakibatkan kehidupan masyarakat memasuki zone rekreatif (hiburan). Kondisi ini juga menjadi pemicu terhadap upaya perubahan sistem pembelajaran di sekolah, yang senantiasa dituntut untuk terus menerus mengikuti perkembangan ilmu pengetahuan dan teknologi yang berkembang pesat, sehingga sekolah yang tetap berkutat pada instruksional kurikulum hanya akan membuat peserta didik gagap melihat realitas yang mengepungnya (Hidayat, 2008).

Beberapa peneliti menyatakan kita belajar, $10 \%$ dari apa yang dibaca;20\% dari apa yang didengar; $30 \%$ dari apa yang dilihat; $50 \%$ dari apa yangdilihat dan didengar, 70\% dari apa yang dikatakan, $90 \%$ dari apa yang dilakukan, sedangkan pembelajaran dengan mempergunakan teknologi audiovisual akan meningkatkan kemampuan belajar sebesar $50 \%$, dari pada dengan tanpa mempergunakan media. Upaya membuat anak betah belajar disekolah dengan memanfaatkan teknologi multimedia, merupakan kebutuhan, sehingga sekolah tidak lagi menjadi ruangan yang menakutkan dengan berbagai tugas dan ancaman yang justru menghambat kemampuan atau potensi dalam diri siswa. Pemanfaatan teknologi merupakan kebutuhan mutlak dalam dunia pendidikan sehingga sekolah benar-benar menjadi ruang belajar dan tempat siswa mengembangkan kemampuannya secara optimal, mampu berinteraksi dan menjadi bagian integral peradaban masyarakat (Wawan dan Dewi, 2010).

Dalam proses mempelajari musik diperlukan sebuah pemahaman yang mendasar. Hal ini dilakukan agar dapat mengaplikasikan teori yang ada dalam musik ke dalam sebuah instrumen. Dalam mempelajari musik dibutuhkan inovasi yang dapat menarik para peserta didik sehingga peserta didik tidak cepat bosan.

Medote pembelajaran berbasis teknologi multimedia yang secara sengaja dan kreatif dirancang untuk membantu memecahkan permasalahan pembelajaran, kiranya merupakan alternatif yang akan banyak memberikan manfaat dalam upaya peningkatan kualitas pembelajaran. Berbagai bentuk pengalaman belajar, baik yang dapat dicapai dalam kelas maupun diluar kelas dan pesan-pesan pembelajaran dalam bentuk teknologi multimedia, yang 
mengemas pesan pembelajaran secara sistemik dan sistematik sehingga dapat diterima oleh siswa dengan baik dan mudah, serta menciptakan pembelajaran yang menyenangkan (enjoyment atau joyful learning), fleksibel dalam dimensi waktu, serta mengembangkan potensi siswa secara individual. (Jonassen, dkk,1999; Hede, 2002). Kurikulum sebagai sejumlah mata pelajaran yang harus ditempuh oleh peserta didik merupakan konsep kurikulum yang banyak mewarnai teori-teori dan praktik pendidikan. Kurikulum sebagai pengalaman belajar mengandung makna bahwa kurikulum adalah seluruh kegiatan yang dilakukan peserta didik baik didalam maupun diluar institusi pendidikan, asal kegiatan tersebut berada dibawah tanggung jawab pengajar (sekolah). Sedangkan kurikulum sebagai suatu program atau rencana pembelajaran pada dasarnya adalah sebuah perencanaan atau program pengalaman siswa yang diarahkan oleh sekolah/institusi, bukan hanya berisi tentang program kegiatan, akan tetapi juga berisi tentang tujuan yang harus ditempuh beserta alat evaluasi untuk menentukan keberhasilan pencapaian tujuan, dan berisi tentang alat atau media yang diharapkan dapat menunjang terhadap pencapaian tujuan. Dengan demikian dapat disimpulkan bahwa kurikulum merupakan seperangkat rencana dan pengaturan mengenai tujuan, isi, dan bahkan pelajaran serta cara yang digunakan untuk mencapai tujuan pendidikan tertentu (UU No. 23 tahun 2003, Bab I pasal 1 ayat 19).

Materi yang diberikan dalam pembelajaran ini adalah mengenai nama dan nilai nada. Teori musik merupakan hal mendasar dalam memainkan musik, sehingga proses pemahamannya harus sesuai dengan kenyamanan peserta didiknya. Penggunaan aplikasi sibelius dalam proses pembelajaran ini dimaksudkan agar peserta didik dapat lebih memahami baik secara visual maupun secara audio.

Kompetensi adalah suatu pengetahuan, keterampilan dan kemampuan atau kapabilitas yang dimiliki oleh seseorang yang telah menjadi bagian dari dirinya sehingga mewarnai perilaku kognitif, afektif dan psikomotoriknya (Sanjaya, 2008). Dengan demikian, maka kompetensi pada dasarnya merupakan perpaduan dari pengetahuan, keterampilan, nilai, dan sikap yang direfleksikan dalam 
kebiasaan berpikir dan bertindak (Sanjaya, 2008).

Pembelajaran merupakan upaya sengaja dan bertujuan yang berfokus kepada kepentingan, karakteristik, dan kondisi orang lain agar orang tersebut dapat belajar dengan efektif dan efisien. (Miarso, 2008). Kata media berasal dari bahasa latin medius yang secara harfiah berarti "tengah, perantara, atau pengantar". Dalam bahasa Arab, media adalah perantara atau pengantar pesan dari pengirim kepada penerima pesan. Media sering juga disebut sebagai mediator yaitu alat yang menyampaikan atau mengantarkan pesan-pesan pembelajaran. Media meupakan kompnen sumber belajar atau wahana fisik yang mengandung materi instruksional di lingkungan yang dapat merangsang siswa untuk belajar.

Dengan demikian dapat disimpulkan bahwa media pembelajaran adalah segala sesuatu yang dapat menyalurkan pesan, dapat merangsang pikiran, perasaan, dan kemauan peserta didik sehingga dapat mendorong terciptanya proses belajar pada diri peseta didik (Sudrajat, 2008).Multimedia pembelajaran dapat diartikan sebagai aplikasi multimedia yang digunakan dalam proses pembelajaran. Dengan kata lain multimedia digunakan untuk menyalurkan pesan (pengetahuan, keterampilan, dan sikap) serta dapat merangsang pikiran, perasaan, perhatian dan kemauan pembelajar, sehingga secara sengaja proses belajar terjadi, betujuan dan terkendali (Amatunisa, 2010).

Dari beberapa defenisi diatas dapat disimpulkan bahwa Pemanfaatan teknologi multimedia dalam pembelajaran merupakan penggunaan media secara majemuk untuk pencapaian kompetensi tertentu, yang didalamnya terdapat proses integrasi berbagai jenis media yang digunakan dalam suatu penyajian yang tersusun secara baik, yang medianya dirancang untuk saling melengkapi sehingga secara keseluruhan media yang digunakan akan menjadi lebih besar perannya dalam proses belajar mengajar, sehingga masyarakat identik dengan teknologi multimedia yang berbasis komputer, interaktif dan pembelajaran mandiri (Mukninan, 2009).

Pengajar dan atau pendidik perlu mengingat bahwa peserta didik yang lebih modern cenderung familiar menggunakan 
internet dibandingkan peserta didik yang sedikit kuno yang kemungkinan kurang nyaman dengan metode pembelajaran berbasis web, untuk mendapatkan hasil terbaik dari proses pembelaaran, peserta didik memerlukan keterampilan dasar komputer, dukungan, dan arahan. Pengajar harus mendesain pembelajaran mereka sedemikian rupa untuk mengefektifkan pembelajaran online dari pada hanya bertujuan berselancar di dunia maya.

Desain program seharusnya memperkaya informasi sehingga dengan metode ini berbagai kalangan terbiasa menggunakan komputer dan sumbersumber online untuk mendukung pekerjaan dan pengembangan profesi yang berkelanjutan. Media elektronik dapat memfasilitasi akses sumber-sumber berbasis bukti. Pengajar harus dimotivasi melalui pelatihan dan dukungan terhadap penggunaan web sistem teknologi informasi lain dalam mengajar.

Berdasarkan fenomena tersebut, maka kemampuan pengajar dan siswa perlu untuk ditingkatkan kualitasnya, terutama jika dikaitkan dengan tuntutan tugas pengajar diera globalisasi saat ini yang ditandai oleh semakin meluasnya penggunaan teknologi multimedia, sehingga penting rasanya untuk meningkatkan kualitas pembelajaran melalui pemanfaatan teknologi multimedia (Singgih, 2009).

SMPN 1 Palembang merupakan salah satu sekolah yang telah banyak meluluskan peserta didik yang mampu memahami multimetia. Beberapa tahun belakangan ini SMPN 1 Palembang sudah dilengkapi dengan fasilitas multimedia dalam pembelajaran yang cukup memadai seperti layanan internet, media audio visual, LCD, OHP, komputer, perpustakaan dan sebagainya. Bila dilihat secara kasat mata banyak mahasiswa yang belum memanfaatkan fasilitas tersebut dengan baik dalam pembelajaran.

Berdasarkan latar belakang diatas dan melihat betapa besarnya manfaat yang dapat diperoleh dari penggunaan teknologi multimedia dalam pembelajaran Musik dan penting dilakukan perubahan terhadap sistem pendidikan, maka peneliti tertarik mengambil penelitian dengan judul "Pemanfaatan Teknologi Multimedia dalam Pembelajaran Musik di SMPN 1 Palembang".

Penelitian ini bertujuan untuk mengetahui bagaimana pemanfaatan 
teknologi multimedia dalam pembelajaran di SMPN 1 Palembang. Hasil penelitian ini dapat digunakan sebagai informasi tambahan bagi ranah pendidikan tingkat pertama, bahwa teknologi multimedia sangat penting dalam proses pembelajaran musik terutama dijaman sekarang.

\section{B. METODE PENELITIAN}

Penelitian ini menggunakan desain penelitian deskriptif yaitu suatu metode penelitian yang bertujuan untuk memberikan gambaran tentang bagaimana pemanfaatan teknologi multimedia dalam pembelajaran Musik di SMPN 1 Palembang. Instrumen dalam penelitian ini berupa kuesioner yang ditujukan untuk mendapatkan informasi tentang karakteristik demografi dan bagaimana pemanfaatan teknologi multimedia dalam pembelajaran Musik di SMPN 1 Palembang.

\section{Populasi dan Sampel}

Populasi dalam penelitian ini semua siswa kelas VII SMPN 1 Palembang yang keseluruhannya berjumlah 90 orang mahasiswa.

Sampel dalam penelitian ini diambil dengan menggunakan tehnik sampel jenuh dimana semua populasi menjadi sampel dalam penelitian ini.

\section{Metode Analisa Data}

Analisa data dalam penelitian ini adalah analisa deskriptif yaitu suatu prosedur pengolahan yang menggambarkan data dengan cara ilmiah dalam bentuk tabel. Analisa ini dimulai dengan tahap editing untuk memeriksa kelengkapan data, kemudian memberikan kode untuk memudahkan dalam tabulasi, selanjutnya data dimasukkan ke dalam komputer untuk di olah dengan menggunakan program statistik komputer. Analisa terhadap masing- masing variabel dilakukan dengan skala interval. Hasil analisa data demografi dan dan pemanfaatan teknologi multimedia dalam pembelajaran Musik akan ditampilkan dalam bentuk tabel distribusi frekuensi dan persentase.

\section{HASIL DAN PEMBAHASAN}

Responden dalam penelitian ini adalah siswa kelas VII SMPN 1 Palembang tahun akademik 2017/2018. Karakteristik responden yang akan dipaparkan 
mencakup usia responden, agama dan suku responden.

Dari hasil analisa data yang dilakukan berdasarkan kelompok usia menunjukkan mayoritas responden berada pada rentang kelompok usia 1315 tahun yaitu sebanyak $(n=85 ; 70.2 \%)$. Berdasarkan agama, responden yang menganut agama islam merupakan mayoritas yaitu sebanyak ( $\mathrm{n}=88 ; 76 \%$. Sedangkan berdasarkan suku, yang terbanyak sejumlah $(n=71 ; 58.7 \%)$. Untuk media cetak, dari 90 responden yang menjawab ya untuk pembelajaran dengan media cetak sangat sederhana dan menghemat biaya sebanyak $(n=80$; 83.5\%), Pembelajaran dengan media cetak lebih mudah dibandingkan dengan menggunakan komputer $(\mathrm{n}=70 ; 57.9 \%)$, fasilitas bahan bacaan tersedia cukup lengkap $(n=83 ; 68.6 \%)$, perpustakaan dapat dimanfaatkan oleh siswa untuk memperoleh informasi dalam bidang keilmuan $(n=79 ; 90.9 \%)$, setiap ada waktu selalu menyempatkan diri ke perpustakaan $(n=84 ; 77.7 \%)$, pembelaran dengan media cetak bersifat monoton dan membosankan $\quad(n=58 ; \quad 56.2 \%)$, membutuhkan waktu yang lama karena harus mencari buku-buku yang sesuai dengan mata pelajaran $(n=40 ; 41.3 \%)$, dan siswa bebas meminjam buku di perpustakaan sebanyak ( $n=74 ; 75 \%)$ Sehingga setelah dikelompokkan menjadi tiga kelompok baik cukup dan kurang diperoleh hasil dari 90 responden, mayoritas responden memanfaatkan teknologi multimedia pembelajaran dengan baik. Dari 90 responden yang menjawab ya tentang fasilitas audio visual seperti TV, VCD, dan OHP tersedia dan dalam keadaan baik $(n=78 ; 81.8 \%)$, pembelajaran di laboratorium di fasilitasi dengan video dan TV ( $n=65 ; 62.0 \%)$, siswa selalu menggunakan OHP dan transparansi $\quad(n=73 ; 69.4 \%)$, menyajikan pesan-pesan visual yang dinamis $(n=80$; 91.7\%), siswa bebas menggunakan media audio visual selama proses belajar mengajar $\quad(n=75 ; \quad 71.1 \%)$ dapat membangkitkan minat dan perhatian siswa $(n=89 ; 90.9 \%)$, penggunaan media audio visual membutuhkan biaya $(n=36 ; 38.8 \%)$, dan media audio visual lebih menarik dalam proses belajar mengajar $(n=89$; 90.9\%). Sehingga setelah dikelompokkan menjadi tiga kategori baik, cukup, dan kurang diperoleh hasil dari 90 
responden,

Mayoritas

memanfaatkan multimedia audio visual dalam pembelajaran dengan baik. menggunakan komputer $(n=86 ; 71.1)$, jumlah komputer memadai dan dalam keadaan baik ( $n=88 ; 72.7 \%$ ), pembelajaran dengan menggunakan komputer lebih menarik dibandingkan dengan media lain ( $n=100 ; 82.6 \%$ ), komputer susah digunakan karena memerlukan keterampilan khusus dalam penggunaannya $(n=81 ; 66.9 \%)$, siswa dapat dengan mudah memperoleh bahan-bahan bacaan melalui internet $(n=107 ; 88.4 \%)$, dapat meningkatkan rasa ingin tahu siswa 109;90.1\%), dapat meningkatkan kulitas pembelajaran ( $n=107 ; \quad 88.4 \%)$, dalam diskusi siswa memaparkan hasil makalah dengan menggunakan komputer ( $n=102 ; 84.3 \%)$, siswa mampu menggunakan komputer dalam pembelajaran $(n=103 ; 85.1 \%)$, tugas kuliah dikirim melalui e-mail ( $n=60 ; 49.6 \%)$.

\section{SIMPULAN}

Hasil penelitian menunjukkan mayoritas siswa SMPN 1 Palembang memanfaatkan teknologi multimedia yang disediakan oleh pihak pendidikan untuk proses belajar mengajar dengan baik.

\section{Daftar Pustaka}

A. Wawan dan Dewi, 2010, Teori dan Pengukuran Pengetahuan, Sikap dan Perilaku Manusia, Yogyakarta : Nuha Medika

Arsyad, A. (2007). Media Pembelajaran. Jakarta : PT. Raja Grafindo Persada.

Arikunto, S. (2006). Prosedur Penelitian Suatu Pendekatan Praktik. Jakarta" Rineka Cipta.

Budiningsih, G. A. (2005). Belajar dan Pembelajaran. Jakarta: Rineka Cipta.

Fajar, I. (2009).Statistik untuk praktisi kesehatan. Yogyakarta : Graha IImu

Hidayat, A. A. A. (2007). Riset Keperawatan dan Teknik Penulisan IImiah. Edisi 2. Jakarta : Salemba Medika. 
Herawani. (2001). Pendidikan Kesehatan dalam Keperawatan. Jakarta: EGC. Nursalam dan Efendi, F. (2008). Pendidikan dalam Keperawatan. Jakarta: Salemba Medika.

Jonassen DH, Peck KL, Wilson BG. 1999. Learning With Technology: A Constructivist Perspective. Ohio: Pub. Merril (Prentice Hall).

Miarso, Yusufhadi. (2008). Menyemai Benih Teknologi Pendidikan. Cetakan Ketiga. Jakarta: Kencana Prenada Media Group.

Mukninan. 2009. Teknologi Pendidikan untuk Peningkatan Kualitas Pembejaranan. Makalah

Notoatmodjo, S. (2005). Metodologi Penelitian Kesehatan. Jakarta: PT. Rineka Cipta.

Purbo,W.O. (2002). E - Learning berbasis PHP dan Mysql. Jakarta : penerbit Elex Media Komputindo

Slameto. (1995). Belajar dan Faktor-faktor yang Mempengaruhinya. Jakarta: rineka Cipta.

Singgih, Santoso, 2009, Panduan Lengkap Menguasai Statistik dengan SPSS 17, Penerbit PT. Elex Media Komputindo, Jakarta.

Sanjaya, Wina. (2008). Pembelajaran dalam Implementasi Kurikulum Berbasis Kompetensi. Jakarta: Kencana.

Sudiyono, A. (2007). Pengantar Evaluasi Pendidikan. Jakarta : PT. Raja Grafindo Persada

Sudrajat, Akhmad. (2008). Pengertian Pendekatan, Strategi, Metode, Teknik dan Model Pembelajaran. Bandung : Sinar Baru Algensindo.

Syafaruddin dan Irwan Nasution. (2000). Manajemen Pembelajaran. Jakarta: Quantum Teaching.

Tilaar. (2006). Standarirsaia Pendidikan Nasional Suatu Tinjauan Teoritis. Jakarta: Rineka Cipta. 